\title{
Building diagnostics versus effectiveness of repairs
}

\author{
Bohdan Stawiski ${ }^{1, *}$, and Tomasz Kania ${ }^{2}$ \\ ${ }^{1}$ Faculty of Environmental Engineering and Geodesy, Wroclaw University of Environmental and \\ Life Sciences, Grunwaldzki sq. 24, 50-365 Wroclaw, Poland \\ ${ }^{2}$ Faculty of Civil Engineering, Wroclaw University of Science and Technology, Wybrzeze \\ Wyspianskiego 27, 50-370 Wroclaw, Poland
}

\begin{abstract}
Building diagnostics before renovation is an important stage in the process of designing and making future repairs and modernization of buildings. Performed hastily, without careful analysis, it may be the cause of wrong decisions about the method of repair. The experience of the person performing the tests usually has an impact on the identification of existing hazards. The article presents an example of the effects of cursory execution of diagnostics on a multi-family residential building. The building was inspected, as it turned out later not precisely, and the causes of damage were wrongly identified. As a result of a cursory diagnosis, works were designed and carried out, which instead of eliminating structural defects have increased them. The causes of errors have been found at the stage of identifying failure, recommendations and repair of a cavity curtain wall. In the summary it was emphasized, that expert experience gained on many examples of differently damaged buildings, under the supervision of a person with experience is necessary for theoretical knowledge to be verified, and the reports were prepared without any faults.
\end{abstract}

\section{Introduction}

Defects appearing often in new buildings are usually the effects of poor supervision over construction work. On the part of designers, a frequent fault is neglecting essential details of the solutions being designed. An example of such a situation is presented in the building which was examined. The assumption that the worker would know what the minimum length of a support for the protective layer should be and how many connecting fittings should be used to connect layers in the triple-layer wall turned out to be incorrect. Frequent faults of designers include neglecting thermal loads. Such cases are presented in the study suggesting establishment of engineering supervision over the work being performed. In the construction industry, as in medicine, the principle 'first do not harm' should be followed and propagated on a broader basis. Any fissures or cracks are unacceptable in the light of binding requirements [1] therefore one must be aware of the issue and make walls in a way

\footnotetext{
* Corresponding author: bohdan.stawiski@upwr.edu.pl
} 
that ensures the certainty that they will not crack, not counting on good fortune that the damage will not be seen.

The problem of repairing any damaged structures is connected with proper recognition of the cause or causes resulting in the damage. The experience of the person examining the building is important and the mechanism of acquiring the experience has been recently eliminated. A case involving superficial investigation of the causes of the appearance of many fissures in walls is presented in the articles [2-4].

After the period of extensive application of three-layer large-panel walls in multi-family buildings, in the late nineties of the last century the designers moved on to three-layer brick walls in which the image of damage on the external side often is not connected with the safety of the building, with the safety of the load-bearing part of the three-layer wall. Any repairs in such walls also require non-conventional solutions. In prefabricated walls, fissures were most often the result of overstiffening the connection between the external and internal layers. In brick walls, most frequently a contrary case occurs with too small a number of connectors per $1 \mathrm{~m}^{2}$ of partition, as well as support of the elevation layer on a too small a length causing the risk of losing stability [5].

\section{Preliminary evaluation of technical condition of walls in the damaged building}

The described examples of damage appeared in a residential multi-family building in use, the external walls of which were made using the three-layer bricked technology.

The problem of cracking in the external elevation of the three-layer wall took place in the area of the wall between the passage under the building and the window located near the passage. This concerns the pillar between the window and window lintel near the tie beam above the ground floor of the building. Visual evaluation of the walls which have a number of cracks always causes concern for the owner.

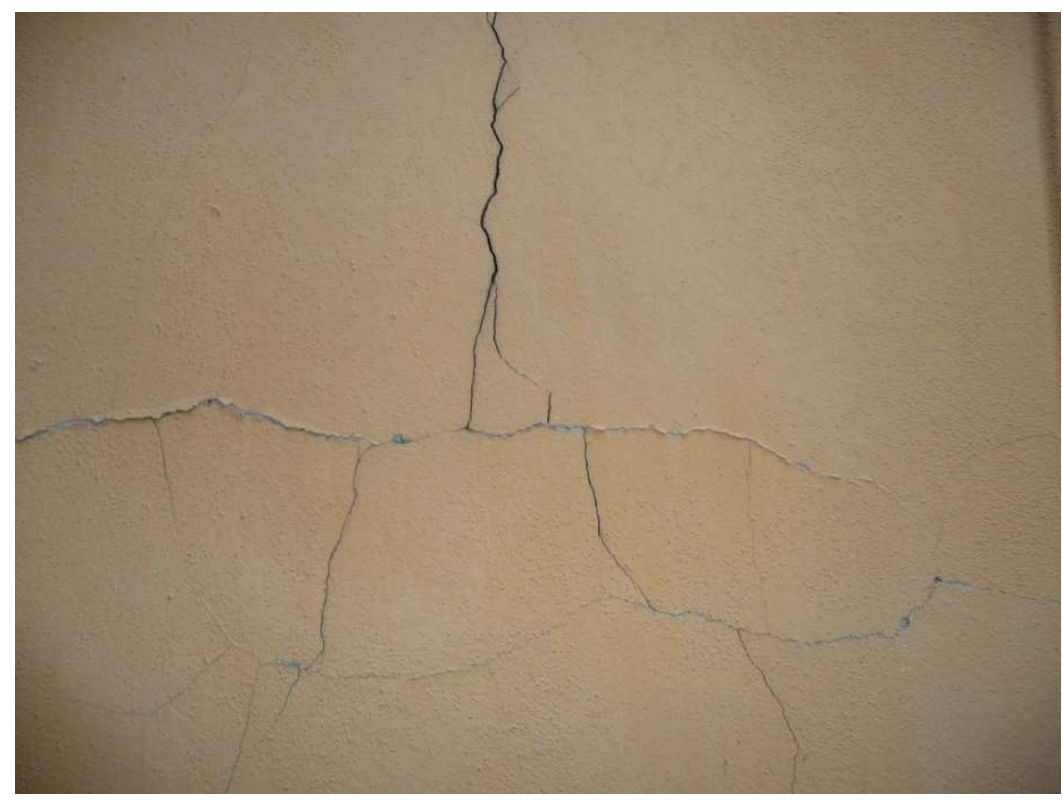

Fig. 1. Cracked surface of the wall above the windows. 
Figure 1 shows cracking in the elevation layer of the wall above the window lintel. The picture shows transverse cracking in the window lintel at the level of the tie beam above the first floor of the building and the network of cracks in the elevation layer of the three-layer brick wall appearing below the tie beam.

Figure 2 shows cracking $1.4 \mathrm{~mm}$ wide in the walls at the level of the tie beam.

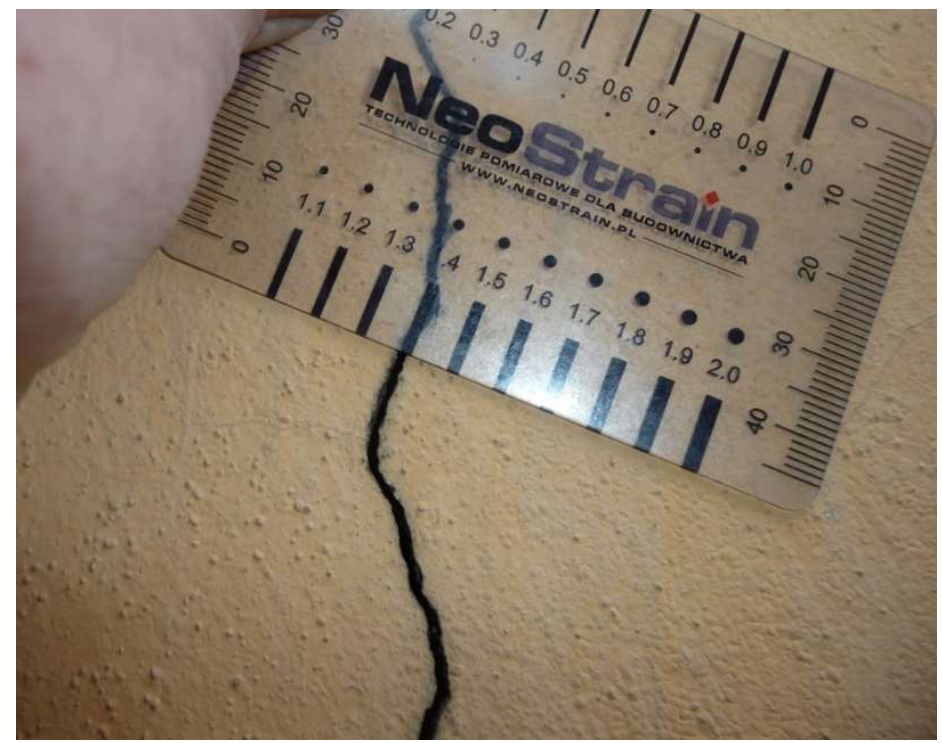

Fig. 2. Width of crack $1.4 \mathrm{~mm}$

Figure 3 shows the condition of fissures in the lintel above the window near the passage under the building.

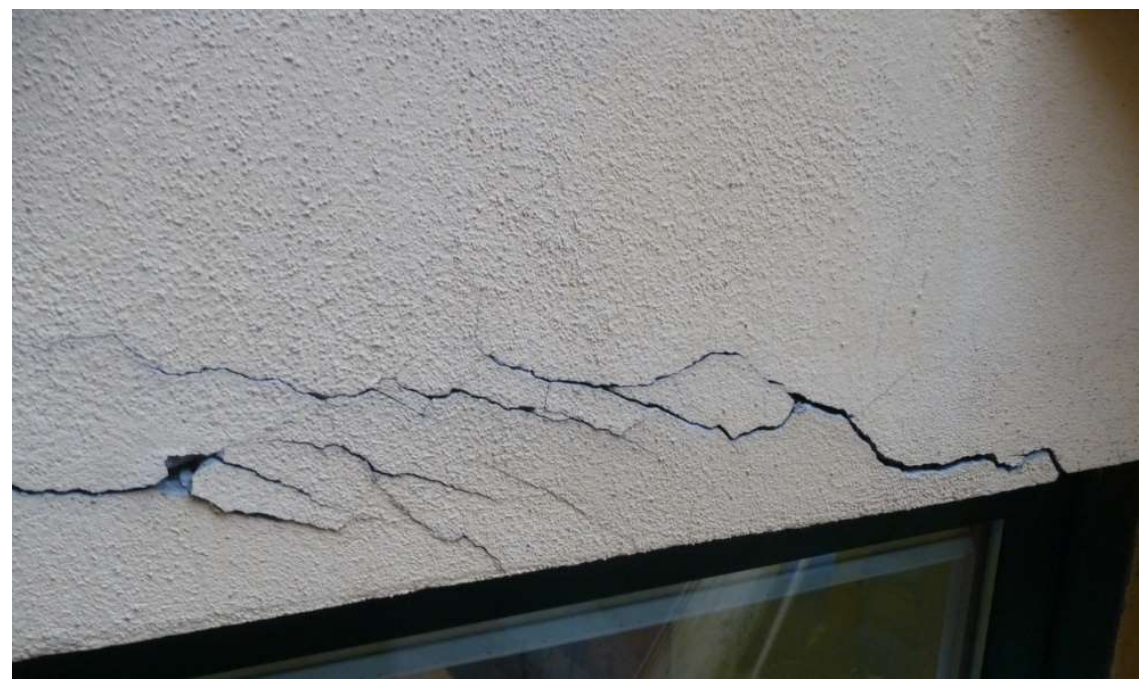

Fig. 3. Cracked lintel above the window.

Fissures of considerable width resulted in local crumbling of external plasters which caused additional concern for the apartment's owner. 
In the period preceding the site inspection in the facility, fissure activity tests were performed. This is indicated by glass 'seals' glued to the walls at the points of damage (fig. 4).
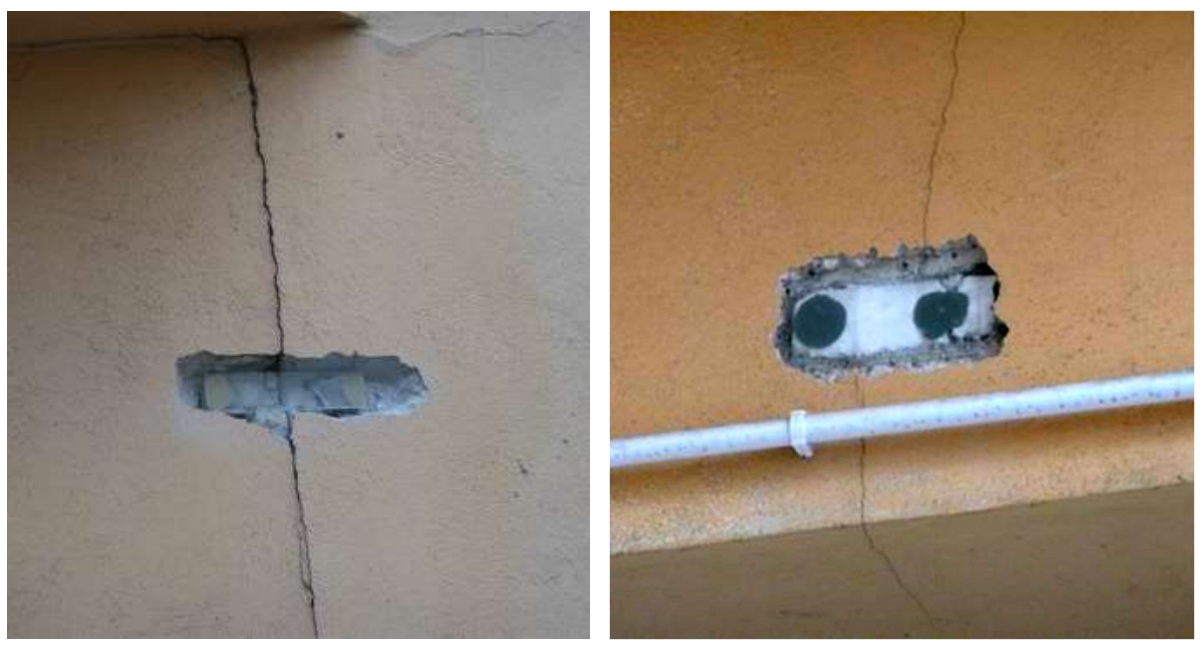

Fig. 4. Glass plates glued perpendicularly to vertical fissures in the external wall of the building.

The 'glass seals' were attached during previous diagnostic work on the building's condition. After a period of several years the glass did not break but the fissures did not stop causing concern. In order to analyse the causes of the damage, changes made in the building after the earlier diagnostic and expert work were examined and the elevation layer of the wall in the places which were damaged was exposed.

\section{Tests on the walls performed to reveal actual causes of damage}

The exposures made in the locations of numerous cracks showed faulty support of the elevation layer of the wall positioned on a support monolithically connected with the reinforced concrete beam of the joist above the passage and with the tie beam above the ground floor of the building. The centre of gravity of the elevation layer is at the end of the support on which this layer is based (fig. 5). Supplementation of the support with plaster, thickness more than $5 \mathrm{~cm}$, cannot be deemed sufficient to transfer distributed load from the external layer of the brick wall.

The exposure made outside of the outline of the tie beam and joist showed an improper method of anchoring the load bearing and curtain layers of the wall. Connection of the wall layers was made using only $2-3$ steel connecting pieces, diameter $5 \mathrm{~mm}$, per $1 \mathrm{~m}^{2}$ of the wall. Please note that the elevation layer of the wall is not only a protective element with aesthetic function. It is affected by considerable forces which are the result of wind thrust and suction and the applied method of connecting it with the load bearing wall must ensure the possibility of transferring horizontal force to the internal layer of the wall. In order to connect the external layer of the wall with the internal one, steel anchors of appropriate plasticity, strength and corrosion resistance should be used. According to the principles of engineering knowledge, in this case the connection of layers with at least 5 steel anchors, minimum diameter $4 \mathrm{~mm}$, should be used. Their number should be concentrated around window and door openings and in corner zones of the building [6]. 


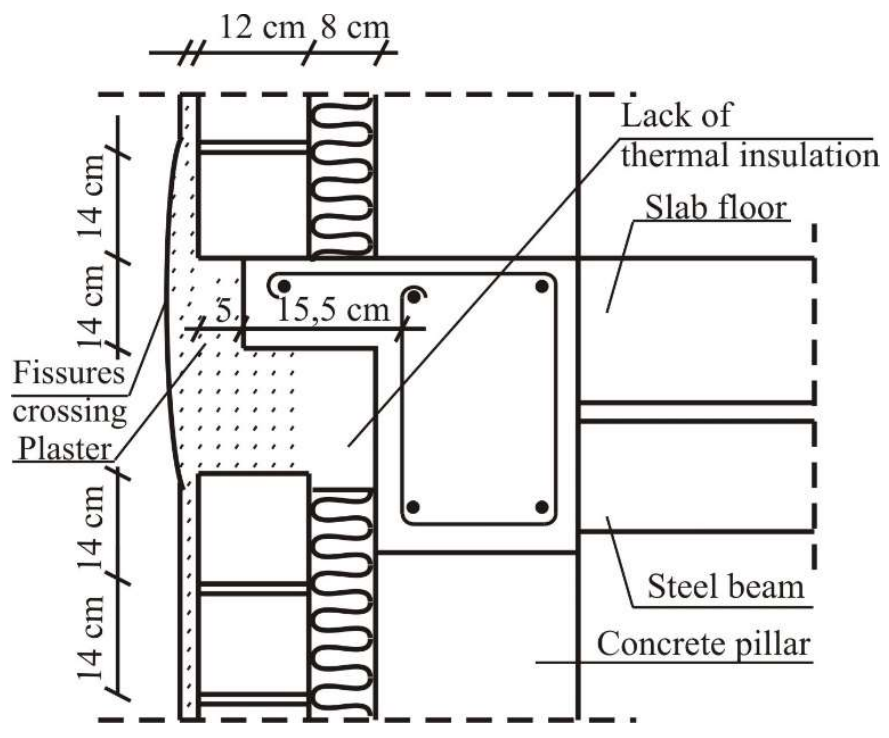

Fig. 5. Unsatisfactory support of the external layer of the curtain wall based on the support of the reinforced concrete beam above the passage under the building.

The long joist, six meters length with cross-section of $60 \times 90 \mathrm{~cm}$ was connected (monolithized) using tie beams with smaller cross-section. The deflection of joist above the passage through the building has been tested with use of the optical leveler. Measured deformation value of this element $\mathrm{fa}=2.16 \mathrm{~cm}$ is equivalent to $1 / 277$ of its length. Deflection of the reinforced concrete beam above the passage through the building also caused deformation of the tie beams monolithized by it on which curtain layers of the external wall were based. As a result of the cooperation of these elements, fissures appeared above the narrow pillar between the windows (fig. 6).

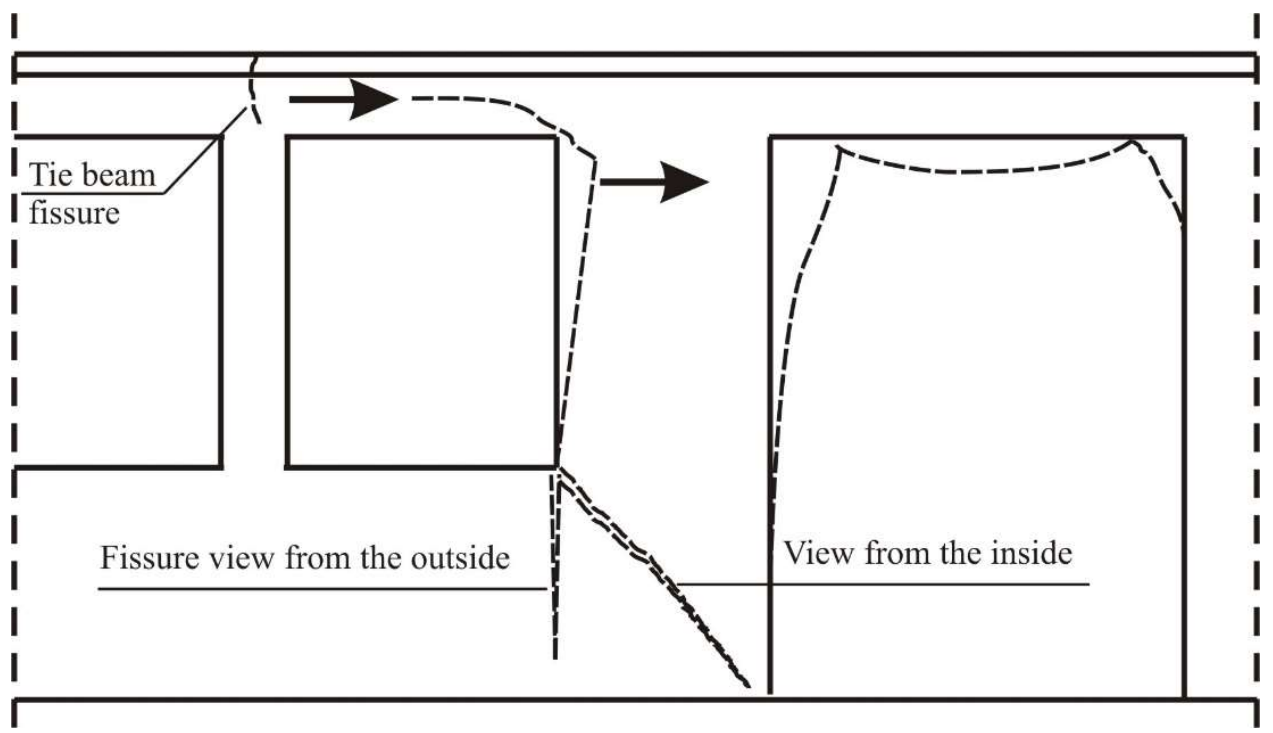

Fig. 6. Progress of fissures in curtain wall of the building in the area of the passage through the building and the pillar between the windows 
Deflection of the girder above the passage caused rotation and cracking of the elevation wall of the extreme pillar (between the window and passage) and the wall above the small pillar between the windows. The author of the building repair design concluded that these cracks caused a safety risk to the small pillar between the windows (the narrower one in fig. 6), probably because of the partition wall located perpendicularly to it and based on the floor from which loads are transferred to the wall, including also to the small pillar. In connection with the cause of the problem as understood in this way, the designer recommended construction of a huge support consisting of two steel poles (each of them consists of two welded 100 channel sections) on both sides of the wall, based on the monolithic bottom floor. Two 220 channel sections were based on the poles (on both sides of the wall) to take over the load from the wall of the higher floor. The poles were anchored with the tie beam using steel expanding bolts and spandrel beams were welded to the poles. Therefore, a stiff steel frame, $6,0 \mathrm{~m}$ wide, was made. The steel frame was mounted in the temporarily unused room at q temperature of $+5.0{ }^{\circ} \mathrm{C}$. When its utilisation started, its usable temperature increased up to $+22.0^{\circ} \mathrm{C}$. Assuming the linear thermal expansion coefficient for steel $\alpha=12 \cdot 10-6\left[1 /{ }^{\circ} \mathrm{C}\right]$, following the formula (1) the change of the length anchored with the steel frame tie beam can be calculated.

$$
x=x_{0} \cdot(1+\alpha \cdot \Delta t)=6000 \cdot\left(1+12 \cdot 10^{-6} \cdot 17\right)=6001,2[\mathrm{~mm}] \text {, }
$$

where:

$x$ - length of steel frame after the temperature change [mm],

$x_{0}-$ length of the steel frame in the installation conditions [mm],

$\alpha$ - thermal expansion coefficient for the material, for steel $\alpha=12 \cdot 10^{-6}\left[1 /{ }^{\circ} \mathrm{C}\right]$,

$\Delta t$ - temperature change $\left[{ }^{\circ} \mathrm{C}\right]$.

According to the calculations presented, the steel frame, $6,0 \mathrm{~m}$ long, stiffly anchored using expanding bolts with tie beam, at a temperature gain $\Delta \mathrm{t}=17.0{ }^{\circ} \mathrm{C}$ changed its length by $1.2 \mathrm{~mm}$. This caused pushing of the tie beam together with the wall in the direction of the outside of the building (fig. 7).

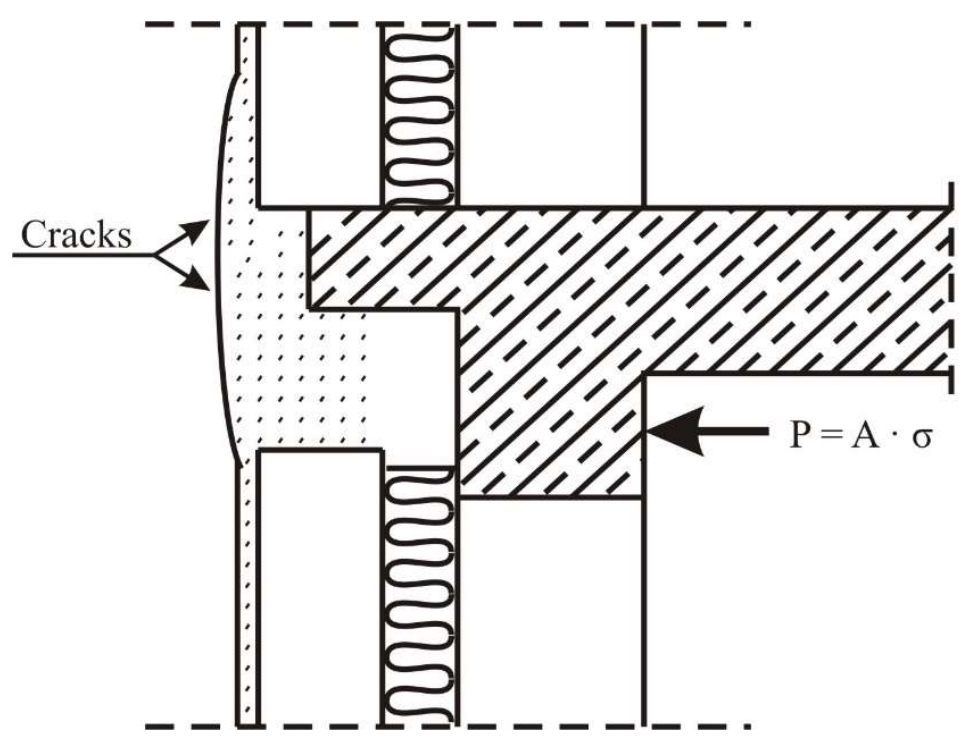

Fig. 7. Deflection of the girder above the passage caused rotation and fissures of the extreme pillar, cracking of this wall and cracking above the small pillar between the windows. 
In the tie beam, in the extension of the mounted steel beams, a fissure, $1.5 \mathrm{~mm}$ wide, appeared. In order to relieve the structure from destructive thermal deformations, it was necessary to separate the tie beam from the steel frame using movement joints, making a gap between the tie beam and the frame.

When exposures were made, also other defects were revealed e.g. lack of thermal insulation on the tie beam, very thick plasters (from 3 to $5 \mathrm{~cm}$ ) which quickly crack and crumble during deformations.

\section{Summary}

It can be concluded with high probability that engineering supervision over construction work performed is still unsatisfactory on many currently erected buildings. Work which requires performance accuracy, such as the minimum length of supporting bricks on the support $(9 \mathrm{~cm}$ per brick $12 \mathrm{~cm}$ wide) should not remain uncontrolled, similarly, the minimum number of connecting pieces between the layers should be controlled $(5 \phi 3 \mathrm{~mm}$ for $60 \mathrm{~mm}$ gap, $5 \phi 5 \mathrm{~mm}$ for a gap up to $150 \mathrm{~mm}$ are recommended) [6]. In the case discussed, both requirements were neglected. The designer did not take care to provide such details in the drawings or in the description and then, when fissures and cracks appeared, he did not analyse the deflection line of the long girder above the passage connected with the tie beams, only hastily recommended 'reinforcement' which again began to destructively affect the structure because thermal expansions were neglected [7]. Similarly, e.g. excessive deflections of floors are not appreciated because they are compliant with requirements for reinforced concrete and the partition walls crack [7-12]. Fissures that occasionally appear or small span cracking of walls generally are not causes for concern, however often the scale of damage is unacceptable for buyers - the more so that under Polish technical conditions $[1,13]$ any cracks are regarded as prohibited. The postulate for permanent improvement of supervision over the quality of construction performed work is still valid. On the other hand, the effectiveness of any repair on damage that appears is dependent on the quality of the completed diagnostics which precede the repair project for each facility.

\section{References}

1. Technical conditions to be met by buildings and their location [Polish law regulations] (Journal of Laws from 2002 No. 75, item 690 with all changes)

2. Orłowicz R., Małyszko L.: Prze. Bud., 2, 30-33 (2002)

3. R. Nowak, R. Orłowicz, Mat. Bud., 11, 72-73 (2017), DOI: 10.15199/33.2017.11.31

4. P. Berkowski, G. Dmochowski, Mat. Bud., 11, 13-15 (2017), DOI: 10.15199/33.2017.11.05

5. B. Stawiski, Masonry structures. Repairs and reinforcements, (POLCEN, Warszawa 2014)

6. B. Lewicki, J. Bielawski, J. Sieczkowski, Masonry buildings. Design rules with calculation examples (COBPBO, Warszawa 1993)

7. B. Stawiski, XXI Conference of Structural Failures, (Szczecin - Miedzyzdroje 2003), 401-406

8. T. Kania, B. Stawiski, Mat. Bud., 11, 101-103 (2015), DOI: 10.15199/33.2015.11.30

9. A.W. Beeby, R.S. Narayanan, Designer handbook to Eurocode 2. Part. 1.1: Design of concrete structures (Thomas Telford House, London 1995) 
10. Ł. Drobiec, Masonry structures according to the Eurocode 6 and related standards. Part 1, (PWN, Warszawa 2013)

11. В.Н. Деркач, Пром. и гражд. стр 6, 62-66 (2013)

12. W. Brameshuber, M. Raupach, Prevention of cracking damages in non-load bearing partition walls and load bearing walls with low load - F 777 (Institut fuer Bauforschung, Aachen, 2006)

13. T. Kania, Researches on the causes of cracking and on fire resistance and acoustic insulation of synthetic gypsum partition walls (Wroclaw University of Technology, 2014) 